\title{
Contribution of tonic vibration reflex to the evaluation and diagnosis of cerebellar disorders
}

\author{
G ABBRUZZESE, M ABBRUZZESE, S RATTO, E FAVALE \\ From the Department of Neurology, University of Genoa, Italy
}

SUMMARY Biceps brachii tonic vibration reflexes were elicited in patients with either focal or diffuse cerebellar damage and spino-cerebellar degenerations. As compared to normal controls, tonic vibration reflex amplitude was reduced in cerebellar patients, particularly in cases with unilateral hemispheric lesion, who exhibited a clear cut tonic vibration reflex asymmetry even when clinical symptoms were mild. These reflexes were absent or very weak in patients with spino-cerebellar degenerations. Muscle vibration induced in most of the patients an enhancement of mild or latent clinical symptoms such as intention tremor, difficulty in muscle relaxation or motor incoordination.

Since the tonic vibration reflex was first described by Eklund and Hagbarth, ${ }^{2}$ several studies have dealt with its possible use as a tool to evaluate patients with neurological disorders. ${ }^{3}$ Conflicting results have been reported on the behaviour of tonic vibration reflexes in cerebellar patients. They were found by some authors to be reduced or absent in patients with cerebellar disorders, particularly on the side of the greater deficit; ${ }^{45}$ they were present but reduced in a case of Friedreich's ataxia, only in the upper limbs where tendon jerks were present. ${ }^{5}$ Hagbarth and Eklund, ${ }^{6}$ however, described in cerebellar patients tonic vibration reflexes "either of normal strength or reduced". Gemba and Sasaki' observed normal or reduced tonic vibration reflexes in cerebellectomised subjects and in patients with cortical cerebellar ataxia, while they could not induce any such reflex in cases of olivopontocerebellar atrophy.

In the present study we have reinvestigated tonic vibration reflexes in patients with various focal or diffuse cerebellar involvement, and in patients with spinocerebellar degenerations, to test the role of cerebellum in eliciting these reflexes and to evaluate their possible contribution to the diagnosis of cerebellar disorders.

\section{Patients and methods}

The study was performed in 20 cerebellar patients (seven

Address for reprint requests: Dr Giovanni Abbruzzese, Clinica Neurologica-Via De Toni, 5, I 16132 Genova, Italy.

Received 8 November 1981

Accepted 12 December 1981 females and 13 males), aged 15-73 (mean 47.5 $\pm 16 \cdot 1$ ) years, and in a group of 20 healthy controls (five females and 15 males), aged $25-75$ (mean $45 \cdot 1 \pm 15 \cdot 0$ ) years.

The cerebellar patients could be classified into three groups (see table): (a) patients with focal cerebellar damage with a unilateral hemispheric syndrome due to vascular or neoplastic lesion (cases 1-7); (b) patients with diffuse cerebellar involvement with an axial syndrome due to cortical atrophy, vascular or infectious diseases (cases 8-14); (c) patients with spinocerebellar degenerations, that is Friedreich's ataxia (cases 15-18), dyssynergia cerebellaris myoclonica (case 19), suspected olivopontocerebellar atrophy (case 20). Diagnosis was on the basis of history and neurological examination, blood and cerebrospinal fluid laboratory tests, electrophysiological investigations and computed tomography scans.

The biceps brachii tonic vibration reflex of both sides was elicited in cerebellar patients and controls by means of a cylindrical vibrator (Heiva, Model TMT 18) (vibration frequency $100 \mathrm{~Hz}$, amplitude $2 \mathrm{~mm}$ ), applied with a constant pressure over the biceps tendon. Subjects were sitting comfortably in a chair, with the head in the midline position and the eyes closed; the forearm, supinated and flexed to $70^{\circ}$ at the elbow joint, was fixed at the wrist on a rigid bar connected to a force transducer (Grass, FT $10 \mathrm{C}$ ), so that an isometric contraction of the biceps developed during vibration. Subjects were instructed to keep relaxed and not to resist any movement feeling they might perceive. The electromyogram of the biceps brachii was recorded by surface electrodes placed over the muscle belly and shielded from the vibrator by an earth lead to reduce the electrical artifacts from the vibrator. The amplified EMG and force transducer signals were monitored on an oscilloscope (Tektronix $502 \mathrm{~A}$ ) and recorded by a polygraph (OTE Biomed., CB6 Recorder). At least five trials were repeated in all the subjects for each side, with an interval between trials of 30 seconds. Vibration was turned off ten 
Table

\begin{tabular}{|c|c|c|c|c|c|c|c|c|c|}
\hline \multirow[t]{3}{*}{ Cases } & \multirow[t]{3}{*}{ Sex } & \multirow{3}{*}{$\begin{array}{l}\text { Age } \\
(y r)\end{array}$} & \multirow{3}{*}{$\begin{array}{l}\text { Duration of } \\
\text { illness }\end{array}$} & \multirow{3}{*}{$\begin{array}{l}\text { Cerebellar } \\
\text { CT scan findings }\end{array}$} & \multirow[t]{3}{*}{ Diagnosis } & \multicolumn{4}{|c|}{ Tonic vibration reflex } \\
\hline & & & & & & \multicolumn{2}{|c|}{ Amplitude (kg) } & \multicolumn{2}{|c|}{ Rise time $(s)$} \\
\hline & & & & & & $R$ & $L$ & $R$ & $L$ \\
\hline 1 & $\mathbf{M}$ & 55 & $2 \mathrm{~m}$ & Right PZ hypodense area & Right cerebellar metastasis & $0 \cdot 678$ & $1 \cdot 523$ & 6.4 & $11 \cdot 3$ \\
\hline 2 & $\mathrm{~F}$ & 70 & $2 \mathrm{~m}$ & Left $\mathrm{H}$ hypodense area & Left cerebellar metastasis & 0.824 & 0.721 & $11 \cdot 6$ & $7 \cdot 8$ \\
\hline 3 & $\mathbf{M}$ & 57 & $1 \mathrm{~m}$ & Right PZ hypodense area & Right cerebellar softening & 1.000 & $2 \cdot 226$ & $7 \cdot 9$ & 8.9 \\
\hline 4 & $\mathbf{M}$ & 64 & $2 \mathrm{~m}$ & Left PZ hypodense area & Left cerebellar softening & 1.726 & $0 \cdot 818$ & $15 \cdot 4$ & $8 \cdot 4$ \\
\hline 5 & M & 47 & $7 \mathrm{yr}$ & $\mathrm{V}$ and left $\mathrm{PZ}$ hypodense & Surgical ablation of chole- & 0.407 & $0 \cdot 268$ & $7 \cdot 6$ & $5 \cdot 1$ \\
\hline 6 & $\mathbf{M}$ & 56 & $1 \mathrm{~m}$ & Left $\mathrm{H}$ hypodense area & Left cerebellar softening & 0.916 & 0.595 & $8 \cdot 8$ & $8 \cdot 1$ \\
\hline 7 & $\mathrm{~F}$ & 43 & $3 \mathrm{~m}$ & Left $\mathrm{H}$ hypodense area & Left cerebellar metastasis & $1 \cdot 142$ & 0.892 & $4 \cdot 9$ & $6 \cdot 1$ \\
\hline 8 & $\mathbf{M}$ & 51 & $1 \mathrm{yr}$ & $\begin{array}{l}\text { Cerebellar atrophy, SS } \\
\text { enlargement }\end{array}$ & Cerebellar atrophy & $1 \cdot 012$ & $1 \cdot 011$ & $12 \cdot 6$ & $12 \cdot 2$ \\
\hline 9 & M & 48 & $6 \mathrm{~m}$ & Normal & Vertebro-basilar insufficiency & 0.649 & 0.660 & $6 \cdot 2$ & $6 \cdot 2$ \\
\hline 10 & $\mathbf{M}$ & 60 & $2 \mathrm{~m}$ & Normal & Creutzfeldt Jacob disease & $1 \cdot 390$ & $1 \cdot 395$ & $8 . \overline{8}$ & $8 \cdot 8$ \\
\hline $11^{*}$ & M & 38 & $3 \mathrm{yr}$ & Corticocerebellar atrophy & Familial corticocerebellar & $1 \cdot 197$ & 0.684 & $10 \cdot 0$ & $9 \cdot 7$ \\
\hline $12^{*}$ & $\mathbf{M}$ & 49 & $10 \mathrm{yr}$ & $\begin{array}{l}\text { Corticocerebellar atrophy, } \\
\text { WM hypodensity, SS }\end{array}$ & $\begin{array}{l}\text { atropny } \\
\text { Familial corticocerebellar } \\
\text { atrophy }\end{array}$ & $1 \cdot 178$ & $1 \cdot 107$ & $9 \cdot 7$ & $10 \cdot 4$ \\
\hline & & & & enlargement & & & & & \\
\hline $13^{*}$ & $\mathbf{M}$ & 42 & $5 \mathrm{yr}$ & $\begin{array}{l}\text { Corticocerebellar atrophy, } \\
\text { WM hypodensity, SS } \\
\text { enlargement }\end{array}$ & $\begin{array}{l}\text { Familial corticocerebellar } \\
\text { atrophy }\end{array}$ & $1 \cdot 100$ & $0 \cdot 561$ & $10 \cdot 7$ & $11 \cdot 3$ \\
\hline 14 & $\mathbf{M}$ & 73 & $1 \mathrm{~m}$ & Normal & Vertebro-basilar insufficiency & $1 \cdot 047$ & $1 \cdot 083$ & $10 \cdot 3$ & $10 \cdot 9$ \\
\hline 15 & $\mathbf{M}$ & 53 & $23 \mathrm{yr}$ & Left $\mathrm{H}$ atrophy & Friedreich's ataxia & Absent $\dagger$ & Absent ${ }^{\dagger}$ & - & - \\
\hline 16 & $\mathbf{F}$ & 16 & $12 \mathrm{yr}$ & Normal & Friedreich's ataxia & 0.410 & $0 \cdot 107 \dagger$ & $7 \cdot 6$ & $6 \cdot 4$ \\
\hline 17 & $\mathbf{F}$ & 25 & $20 \mathrm{yr}$ & Normal & Friedreich's ataxia & Absent ${ }^{\dagger}$ & Absent ${ }^{\dagger}$ & - & - \\
\hline 18 & $\mathbf{F}$ & 31 & $21 \mathrm{yr}$ & WM hypodensity & Friedreich's ataxia & Absent ${ }^{\dagger}$ & $0.230 \dagger$ & - & $12 \cdot 0$ \\
\hline 19 & $\mathbf{F}$ & 15 & $12 \mathrm{yr}$ & Normal & Dyssynergia cerebellaris & $0 \cdot 270$ & $0 \cdot 307$ & $6 \cdot 4$ & $5 \cdot 1$ \\
\hline 20 & $\mathbf{F}$ & 58 & $4 \mathrm{yr}$ & $4 \mathrm{~V}, \mathrm{TC}$ and $\mathrm{VC}$ dilatation & OPCA (?) & 0.584 & $0 \cdot 342$ & 13.4 & 9.0 \\
\hline
\end{tabular}

${ }^{*}$ Patients $11,12,13$ were brothers.

†With facilitatory voluntary contraction.

$\mathrm{V}=$ Vermis; $\mathrm{PZ}=$ Paramedian zone $; \mathrm{H}=$ Hemisphere $; \mathrm{V}=4$ th ventricle $; \mathrm{TC}=$ Truncal cisterns; $\mathrm{SS}=\mathrm{Subarachnoid} \mathrm{spaces} ; \mathrm{WM}=$ White matter; OPCA = Olivopontocerebellar atrophy.

seconds after the maximal plateau tension was developed. The mean values of both tonic vibration reflex amplitude (that is the developed tension) and rise time to plateau tension were measured. Results were analysed by Student's $\mathrm{t}$ test.

\section{Results}

\section{NORMAL CONTROLS}

Tonic vibration reflexes could be elicited for biceps brachii in every normal subject. The mean amplitude was: $1.496 \pm 0.519 \mathrm{~kg}$ in the right side and $1.491 \pm 0.553 \mathrm{~kg}$ in the left side, no difference being observed between the two sides $(t=0.03$ ) (fig 1 , upper traces). The mean rise time was: $8.7 \pm 2.9 \mathrm{~s}$ on the right side and $8.3 \pm 3.5 \mathrm{~s}$ on the left side, without any asymmetry $(t=0.33)$.

\section{CEREBELLAR PATIENTS}

1 Patients with unilateral focal lesion The mean tension developed by vibration in the biceps brachii ipsilateral to the cerebellar lesion was $0.710 \pm 0.237$ $\mathrm{kg}$, while on the normal side it was $1.252 \pm 0.614$ $\mathrm{kg}$, the difference between the two sides being significant $(t=2 \cdot 17, \mathrm{p}<0.05)$. Compared to the mean amplitude of normal controls, the tonic vibration reflex on the affected side of cerebellar patients was reduced $(t=3 \cdot 76, \mathrm{p}<0.001)$ (fig 1 , lower traces), no reduction being observed in the normal side $(t=0.99)$. The mean rise time was $7 \cdot 1 \pm 1.2 \mathrm{~s}$ on the affected side and $9.7 \pm 3.3 \mathrm{~s}$ on the normal side; the difference was significant $(t=2 \cdot 53, \mathrm{p}<$ $0 \cdot 05)$. However, the rise time of the cerebellar patients was not statistically different from values of normal controls $(t=1 \cdot 16)$. A clear-cut asymmetry of the EMG recording amplitude was observed only in patients 4,5 and 7 of this group (see fig 1, lower traces). Two patients (cases 2 and 7) showed marked difficulties in relaxation after that vibration was stopped. Relaxation was delayed, or more gradual than normal, often occurring stepwise and sometimes even absent.

2 Patients with diffuse cerebellar involvement No asymmetry of tonic vibration reflex amplitude was observed between the two sides (right side: $1 \cdot 081 \pm$ 


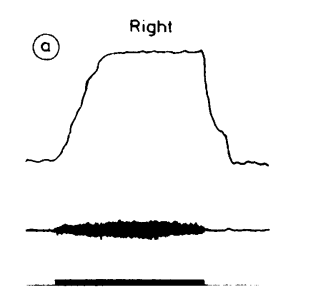

(b)
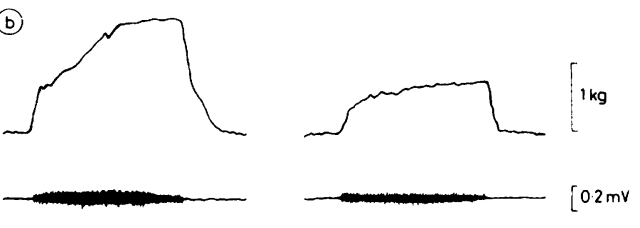

Tonic vibraion reflexes elicited in the right ande

Fig 1 Tonic vibration reflexes elicited in the right and left biceps brachii of (a) a normal subject and (b) a patient with left cerebellar hemisphere lesion (case 4). Upper traces: active torque developed by flexion of the forearm sensed isometrically by force transducer. Lower traces: EMG activity of biceps brachii recorded by surface electrodes. Bars indicate vibration periods. A reduction of tonic vibration reflex amplitude and a clear cut asymmetry of EMG recordings are present in the pathological (left) side of the cerebellar patient.

$0.227 \mathrm{~kg}$, left side: $0.927 \pm 0.303 \mathrm{~kg} ; t=0.98$ ) even if in patients 11 and 13 tonic vibration reflexes were particularly reduced in the side of greater deficit. The reflexes on both sides, however, were reduced as compared to normal controls $(t=2 \cdot 34, \mathrm{p}<0.05)$. The mean rise time was $9.7 \pm 1.9 \mathrm{~s}$ on the right side and $9.8 \pm 1.8 \mathrm{~s}$ on the left side, without either asymmetry $(t=0 \cdot 16)$ or differences versus normal controls $(t=0 \cdot 91)$. Patients 8 and 11 showed relaxation difficulties after vibration was stopped and an evident "intention" tremor was induced by vibration in patients 8 and 10 (fig 2).

3 Patients with spinocerebellar degenerations Tonic vibration reflexes were absent in two patients with Friedreich's ataxia (cases 15 and 17), even when they were asked to exert a facilitory mild voluntary contraction of the biceps brachii. Very weak reflexes could be elicited in the other two Friedreich patients (cases 16 and 18), at least on one side (fig 3), and in the patients with dyssynergia cerebellaris myoclonica (case 19) and olivopontocerebellar atrophy (case 20). This last patient showed relevant relaxation difficulties and a vibration induced tremor.

\section{Discussion}

In the present study we have shown that the biceps brachii tonic vibration reflexes of patients with cere-

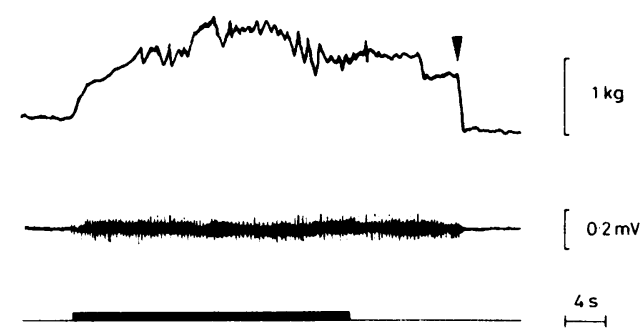

Fig 2 Biceps brachii tonic vibration reflex in a patient with an axial cerebellar syndrome (case 8). Upper and lower traces as in fig 1. Bar indicates vibration period. The rough irregularities of active torque signal reflect an evident intention tremor induced by vibration. Muscle contraction persisted after vibration was stopped; relaxation, irregular and delayed, was completed only when the patient was asked to relax voluntarily (arrow).

bellar disorders are reduced in amplitude, thus confirming previous reports ${ }^{56}$ pointing to a possible role of the cerebellum in eliciting the reflex.

It is generally accepted that the cerebellum, receiving extensive group I afferent projections, increases (through its influence on the $\gamma$-system) the sensitivity of the muscle spindles to stretch and vibration, ${ }^{\mathbf{8}}$ and it has been shown in cats and monkeys that cerebellar lesions may induce a depression of tonic $\gamma$-motoneurone activity, ${ }^{10}$ leading to a disturbance of $\alpha-\gamma$ linkage. Only the persistance of the tonic vibration reflex in the cat after partial cerebellectomy" seems to contrast with such a hypothesis. However, in spite of the discrepancies between the findings in cat and man, it is not surprising that the reflex, providing a method for testing the excitability of tonic motoneurones, might be impaired in patients with cerebellar lesions.

Various hypotheses may be suggested to relate cerebellar damage with impairment of tonic vibration reflexes. Since vestibulospinal and reticulospinal tracts have been shown to be the main pathways responsible for facilitation and maintenance of tonic vibration reflexes in the cat, ${ }^{12-15}$ a lesion of the archicerebellum might be responsible for reflex reduction. On the other hand, group I afferent fibres are known to project to the intermediate or paramedian zone of the cerebellum, ${ }^{16}$ and hypotonia in cerebellar disorders occurs mainly in lesions of the neocerebellum, ${ }^{17}$ so that it could be postulated that a lesion of the deep cerebellar nuclei (dentatus and interpositus), influencing the static $\gamma$-system through pyramidal and rubrospinal pathways, is to some extent involved in tonic vibration reflex depression. In our study, patients with a unilateral focal lesion (placed in four cases in the paramedian zone) showed the greatest impairment of tonic vibration reflexes. However, this reflex also was reduced in 

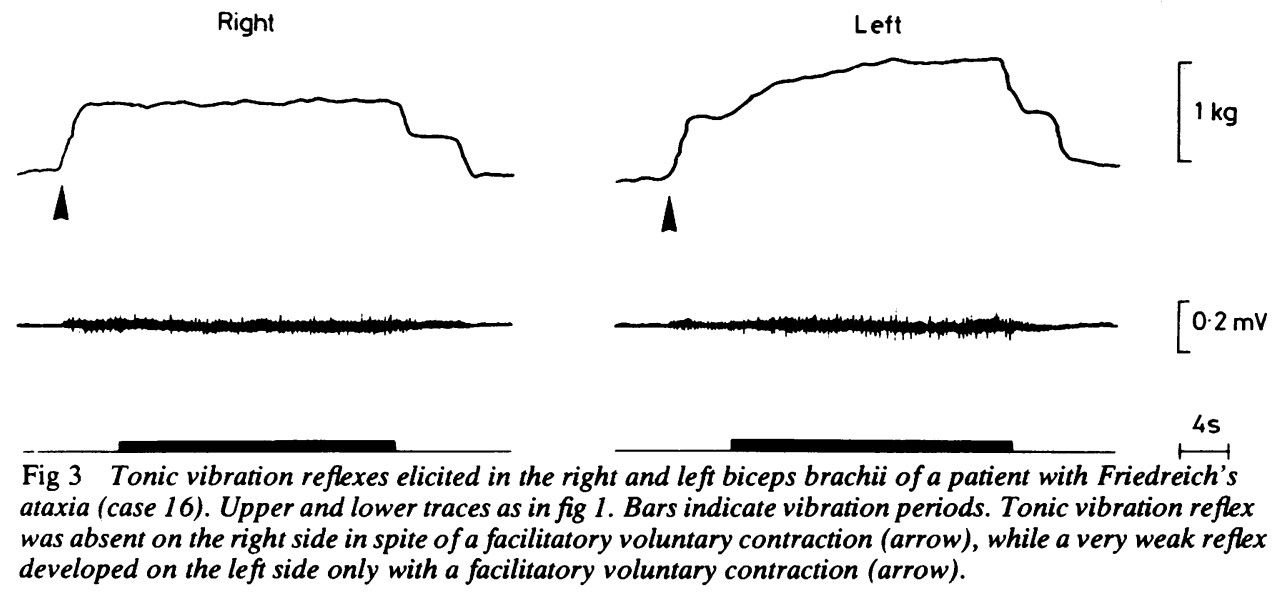

patients with diffuse cortical atrophy. To relate tonic vibration reflex impairment to a specific cerebellar lesion does not seem therefore to be possible.

The relevance of lesions affecting connections of the cerebellum with other parts of the central nervous system should not be disregarded, as suggested by Gemba and Sasaki.' In our study, the tonic vibration reflexes of patients with spinocerebellar degenerations were absent or barely detectable, even when the tendon jerks were still present in the examined limb. No correlation exists between the behaviour of the tonic vibration reflex and tendon reflexes, ${ }^{18}$ since the former could be demonstrated even in patients with clinically absent tendon jerks, ${ }^{5}$ or in patients with benign areflexia. ${ }^{19}$ The interruption of proprioceptive pathways in the spinal cord or brain stem of patients with Friedreich's ataxia is likely to be relevant to the suppression of tonic vibration reflexes.

Although the integrity of cerebellum is not likely to be necessary for eliciting tonic vibration reflex,,$^{12-15}$ our findings demonstrate that a lesion, either focal or diffuse, primarily situated in the cerebellum, removes a facilitatory effect on tonic vibration reflex contractions. The reduction of tonic vibration reflex amplitude was particularly evident ipsilateral to the side of cerebellar lesion or, as previously observed, ${ }^{5}$ of greater deficit. Unlike Gemba and Sasaki,' we could observe a clear cut asymmetry of tonic vibration reflex amplitude in all the subjects with unilateral cerebellar lesions. A possible explanation for the discrepancy of these results could be the greater reliability of torque recordings as compared to EMG recordings. In fact tonic vibration reflex depression could be observed even in cases with mild cerebellar symptoms (case 4) or in cases almost asymptomatic (case 7 ). Since the reliability and reproducibility of tonic vibration reflexes have beèn repeatedly confirmed ${ }^{20-22}$ and no amplitude asymmetry was observed in normal subjects, ${ }^{18}$ measurements of amplitude have proved to be a useful diagnostic parameter. On the contrary, the rising time to plateau tension was found to be slightly reduced only in the side ipsilateral to cerebellar lesion, but not significantly as compared to normal controls. Johnston et al, ${ }^{21}$ showed, however, that in weaker tonic vibration reflexes the plateau tension is reached more quickly, probably because less motor units are recruited.

Besides quantitative measurements of tonic vibration reflex parameters, muscle vibration induced in most of the cerebellar patients abnormal motor effects, accentuating subclinical symptoms like intention tremor or motor incoordination. In particular, a striking difficulty in relaxation was noticed after vibration was stopped, probably because of delay and slowness of the intervention of antagonistic muscles, resembling the classical difficulty of cerebellar patients to stop voluntary movements. ${ }^{23}$

Recording tonic vibration reflexes may therefore help in the diagnosis of cerebellar lesions even in patients with mild or latent clinical symptomatology.

\section{References}

' Eklund G, Hagbarth K-E. Motor effects of vibratory muscle stimuli in man. Electroencephalogr Clin Neurophysiol 1965;19:619.

${ }^{2}$ Hagbarth K-E, Eklund G. Motor effects of vibratory stimuli in man. In: Granit R, ed. Proceedings of first Nobel Symposium. Stockholm: Almqvist and Wiksell, 1966:177-86.

${ }^{3}$ Bishop B. Vibratory stimulation. Part II Vibratory stimulation as an evaluation tool. Physical Ther 1975;55:28-34.

${ }^{4}$ De Gail P, Lance JW, Neilson PD. Differential effects on tonic and phasic reflex mechanisms produced by 
vibration of muscles in man. J Neurol Neurosurg Psychiatry 1966;29:1-11.

${ }^{5}$ Lance JW, De Gail P, Neilson PD. Tonic and phasic spinal cord mechanisms in man. J Neurol Neurosurg Psychiatry 1966;29:535-44.

- Hagbarth K-E, Eklund G. The effects of muscle vibration in spasticity, rigidity and cerebellar disorders. $J$ Neurol Neurosurg Psychiatry 1968;31:207-13.

${ }^{7}$ Gemba H, Sasaki K. Tonic vibration reflex and cerebellar disorders. Exper Neurol 1978;60:213-20.

${ }^{8}$ Granit R. The basis of motor control. New York: Academic Press, 1970.

9 Gilmann S, McDonald WI. Cerebellar facilitation of muscle spindle activity. J Neurophysiol 1967;30: 1494-512.

${ }^{10}$ Gilmann S. Fusimotor fiber responses in the decerebrate cat. Brain Res 1969;14:218-21.

"Matthews PBC. Reflex activation of the soleus muscle of the decerebrate cat by vibration. Nature 1966;209: 204-5.

12 Gillies JD, Burke D, Lance JW. The tonic vibration reflex in the cat. $J$ Neurophysiol $1971 ; 34: 252-62$.

${ }^{13}$ Gillies JD, Burke D, Lance JW. Supraspinal control of tonic vibration reflex. J Neurophysiol 1971;34:302-9.

${ }^{14}$ Andrews C, Knowles L, Lance JW. Corticoreticulospinal control of the tonic vibration reflex in the cat. $J$ Neurol Sci 1973;18:207-16.
${ }^{15}$ Andrews C, Knowles L, Hancock J. Control of the tonic vibration reflex by the brain stem reticular formation in the cat. $J$ Neurol Sci 1973;18:217-26.

${ }^{16}$ Brodal A. Neurological anatomy in relation to clinical medicine. London: Oxford University Press, 1969.

17 Dow RS, Moruzzi AG. The physiology and pathology of the cerebellum. Minneapolis: Minnesota University Press, 1958.

${ }^{18}$ Hagbarth K-E. The effects of muscle vibration in normal man and in patients with motor disorders. In: Desmedt JE, ed. New developments in electromyography and clinical neurophysiology. Vol. 3. Basel: Karger, 1973:428-43.

${ }^{19}$ Abbruzzese G, Abbruzzese M, Favale E, Ratto S. Tonic vibration reflex in Holmes-Adie syndrome: an electrophysiological study.J Neurol Neurosurg Psychiatry 1979;42:943-7.

${ }^{20}$ Eklund G, Hagbarth K-E. Normal variability of tonic vibration reflexes in man. Exper Neurol 1968;16:80 92.

${ }^{21}$ Johnston RM, Bishop B, Coffey GH. Mechanical vibration of skeletal muscles. Physical Ther 1970;50:499505.

${ }^{22}$ Goldfinger GH, Schoon CG. Reliability of the tonic vibratory reflex. Physical Ther 1978;58:46-50.

${ }^{23}$ Holmes G. The cerebellum of man. Brain 1939;62:1-30. 